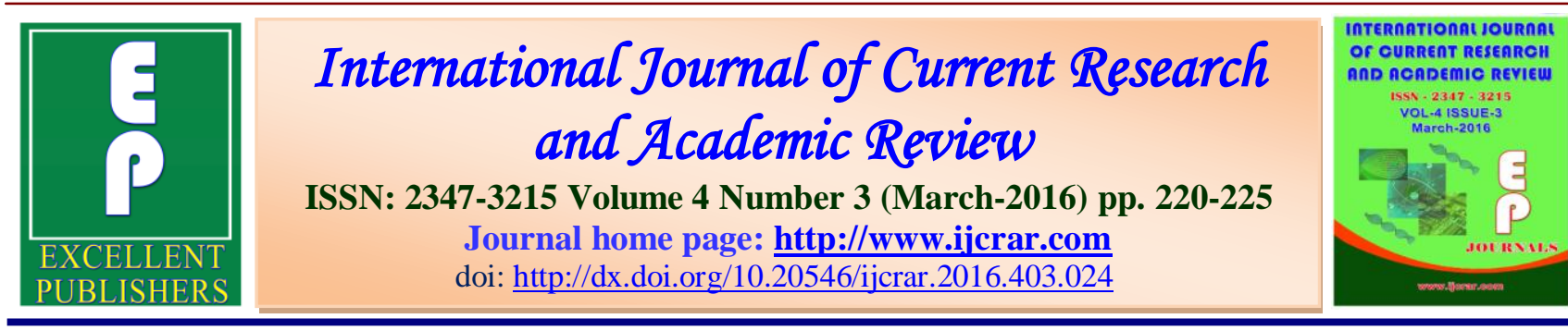

\title{
Evaluation of volatile and intravenous anesthetics effects on the hemodynamic state in children undergoing cochlear implant surgery
}

\section{Masoud Naderpour ${ }^{1}$, Yalda Jabbari Moghaddam ${ }^{1}$, Mehdi Banaei ${ }^{1}$, Kasra Tavasoli ${ }^{1}$,} Reyhaneh Abri ${ }^{2}$, and Mahin Seyed Hejazi ${ }^{2}$ *

${ }^{1}$ Department of ENT, Imam Reza Hospital, Faculty of medicine, Tabriz University of Medical Sciences, Iran

${ }^{2}$ Department of Anesthesiology, Pediatric Hospital, Faculty of medicine, Tabriz University of Medical Sciences, Iran

*Corresponding author

\begin{tabular}{|c|c|}
\hline KEYWORDS & $\mathbf{A} B \mathbf{S} T \mathbf{R} A \mathbf{C}$ \\
\hline $\begin{array}{l}\text { Cochlear } \\
\text { Implant, } \\
\text { Hemodynamic } \\
\text { State, } \\
\text { Pediatric } \\
\text { Anesthesia }\end{array}$ & $\begin{array}{l}\text { Congenital hearing loss affects about } 1 \text { in every } 1000 \text { live births. Cochlear implant is } \\
\text { an effective therapeutic method for aural rehabilitation in patients suffering severe to } \\
\text { profound hearing loss. The aim of this study was to compare the effects of the } \\
\text { intravenous and inhalation anesthesia techniques on neuro-auditory threshold and } \\
\text { stapedial reflex threshold responses. After winning the approval of the ethics } \\
\text { committee of the university and obtaining informed consents, } 110 \text { patients with } \\
\text { severe or profound bilateral sensorineural hearing loss, who were candidates for } \\
\text { cochlear implant surgery were randomly selected and included in the clinical trial. In } \\
\text { this trial, the effects of the total intravenous and inhalation anesthesia techniques on } \\
\text { hemodynamic state of patients with cochlear implants. Variations in systolic and } \\
\text { diastolic blood presses and mean arterial blood pressure were measured in both } \\
\text { groups, and the FlACC scores of patients were examined upon entrance to recovery, } \\
\text { and half an hour and one hour after examinations. In the } 110 \text { children in the two } \\
\text { groups, no significant difference was observed in terms of the following parameters: } \\
\text { age; weight; duration of anesthesia and surgery; mean FLACC scores upon entrance } \\
\text { to recovery, and half an hour and one hour after examinations. No anesthesia side } \\
\text { effect was observed in the two groups. During the surgery, it is important to the } \\
\text { surgeon that the patient's blood pressure remains low so that the surgery is improved. } \\
\text { Hence, selection of the proper medicine for induction and hypotension control is } \\
\text { important. Our results suggest that during the cochlear implant surgery, use of } \\
\text { inhalation anesthetics should be avoided for achieving proper hypotension because } \\
\text { those dosages of inhalation drugs, which lead to hypotension, can suppress or even } \\
\text { fully eliminate stapedius reflex. }\end{array}$ \\
\hline
\end{tabular}

\section{Introduction}

Congenital hearing loss affects about every one in 1000 live births. Approximately 4\% of 10000 children suffer severe to profound hearing loss, which is defined as hearing threshold of $70 \mathrm{db}$ in audiometer with pure tone. 
Cochlear implant (CI) is an effective treatment for restoring hearing in patients with severe to profound hearing loss [1]. The prostheses implanted in the cochlea allow patients with profound sensorineural deafness hear by stimulating the auditory nerves $[1,7]$. To adjust the external implant system, the audiometrist needs to use the ECAP and ESRT domains obtained during cochlear implant [3].

In addition, one of the most important concerns of a cochlear implant surgeon is ensuring proper place of prosthesis, and in this case the ECAP and ESRT values obtained during surgery are also vital $[2,4]$.

Stapedius or acoustic reflex is an autonomic reflex, which protects the ear against adverse effects of loud sounds. Electric stimulation of stapedius reflex during surgery is used to determine the Most Comfortable Listening Level (MCL) for humans. Adjustment of MCL to an intolerable level leads to the patient's distress and lack of adaptation of the patient to the cochlear implant [2].

Severe to profound congenital hearing loss is prevalent among children. Moreover, cochlear implant surgery is an effective treatment for restoring hearing of children. Therefore, to prevent the adverse effects of improper adjustment of prosthetics during surgery (which is carried out through stapedius reflex and neural response threshold checks), we decided to study the effects of inhalation anesthesia with Sevoflurane and total intravenous anesthesia (TIVA) with BBB on hemodynamic status of patients during of surgery.

\section{Materials and Methods}

In a clinical trial, which was conducted in Tabriz on patients with cochlear implant, effects of the inhalation and TIVA anesthesia techniques on hemodynamic status of patients during of surgery in patients with cochlear implant (CI) were studied.

The study population included children aging from 6 months to 7 years, who had a physical status of ASA_IoII and visited the surgery room of Tabriz Vhildren's Hospital to receive $\mathrm{CI}$ treatment. All of the children with severe to profound sensorineural hearing loss were included in the study.

Children that demonstrated side effects of drugs used in the researcher were omitted. Based on Crawford's study (2008), in which stapedius reflex suppression levels with Propofol and Desflurane 1.5 anesthetic drugs were reported to be $90 \%$ and $52 \%$, the sample size was calculated for each group considering $\alpha=0.0 \mathrm{~s}$ and power $=80 \%$. To expand the study, the total sample size was 50 , and a total of 55 patients were eventually put in each group.

The randomization method was used online in the Random_List_Generator software. The randomization list was submitted to a person that was not in the study, and allocation of patients to each group remained secret to the end of the research.

After obtaining the informed consent of parents of the 50 cochlear implant children, who had a physical status of ASA-IoRII and aged between 6 month and 7 years, the children were included in the study Prior to induction, all patients received intravenous Fentanyl $\left(\frac{1 \mu g}{k}\right)$ and Midazolam $\left(\frac{0.05 m g}{k}\right)$ as premedication. At the time of vising the surgery room, the patients were exposed to standard monitoring (Pulse Oximeter, blood pressure measurement, electrocardiography, and EECO). In all patients, anesthesia induction was carried out through injection 
Int.J.Curr.Res.Aca.Rev.2016; 4(3): 220-225

of Lidocaine $\left(\frac{1 m g}{k}\right)$, Propofol $\left(2-\frac{3 m g}{k}\right)$, and Atracuriom $\left(\frac{0.05 m g}{k}\right)$. Afterwards, the patients received the two anesthesia maintenance methods randomly.

In the first group (55 patients), anesthesia was maintained through Remifentanil $\left(0.2-\frac{\frac{0.5 \mu g}{k g}}{\min }\right)$ and Propofol $\left(100-\frac{\frac{150 \mu g}{k g}}{\min }\right)$ infusion. In the second group, anesthesia was maintained with Sevoflurane inhalation gas with a concentration of $1.2 \%-1.5 \%$. Both groups received the $\mathrm{N} 20-\mathrm{O} 2$ mix with a concentration of $50 \%-50 \%$ during the anesthesia. To conserve the thermocapi patients were subjected to mechanical pentilation.

\section{Results and Discussion}

In a study, which was carried out on 110 patients with cochlear implants in ENT Department of Tabriz University of Medical Sciences the following results were obtained.
A total of 55 patients were put in group A and 55 patients were studied in group B.

In group B, 35 children were male and 20 were female. In group A, 27 children were male and 28 were female $(\mathrm{P}=0.124)$.

The average age of children in groups $\mathrm{A}$ and $\mathrm{B}$ was $3.45 \pm 0.98$ years and $3.78 \pm 1.08$ years, respectively $(\mathrm{P}=0.101)$.

The hemodynamic statuses of patients of the two groups are shown in tables (1) to (4). In Table (1), the systolic blood pressures of patients in the two groups before and after the surgery are presented. These results reveal that except for the periods 15,30 and 45 minutes after induction, when the mean SBP of group A was significantly higher than group $\mathrm{B}$, there was no significant difference between the two groups at other times. Concerning the DBP statuses of patients of the two groups (Table 4), it shall be stated that only DBP levels 30 and 165 minutes after induction were significantly higher in group A than group B, and no significant difference was observed between the study groups at other times.

Table.1 Systolic Blood pressure of patients between two groups

\begin{tabular}{lccc}
\hline & $\begin{array}{l}\text { Group } \\
\text { Sevofloran }\end{array}$ & Remifantanil & \\
\hline Before induction & $97.17 \pm 10.34$ & $100.75 \pm 18.67$ & 0.231 \\
After Induction & $93.93 \pm 10.61$ & $91.93 \pm 11.30$ & 0.343 \\
15 min after Induction & $90.95 \pm 9.39$ & $87.22 \pm 9.75$ & 0.044 \\
30 min after Induction & $91.04 \pm 9.60$ & $86.36 \pm 9.93$ & 0.014 \\
45 min after Induction & $89.56 \pm 8.39$ & $85.13 \pm 9.86$ & 0.012 \\
60 min after Induction & $90.91 \pm 10.27$ & $87.22 \pm 10.18$ & 0.061 \\
75 min after Induction & $90.22 \pm 10.36$ & $89.58 \pm 9.18$ & 0.734 \\
90 min after Induction & $90.24 \pm 9.72$ & $90.78 \pm 9.03$ & 0.764 \\
105 min after Induction & $90.14 \pm 9.25$ & $91.14 \pm 9.13$ & 0.590 \\
120 min after Induction & $91.60 \pm 11.60$ & $92.28 \pm 11.50$ & 0.795 \\
135 min after Induction & $90.68 \pm 11.40$ & $92.15 \pm 11.44$ & 0.645 \\
150 min after Induction & $88.50 \pm 9.44$ & $92.39 \pm 9.51$ & 0.344 \\
165 min after Induction & $91.50 \pm 2.52$ & $92.23 \pm 8.56$ & 0.871 \\
180 min after Induction & $86.67 \pm 6.43$ & $99.25 \pm 14.08$ & 0.216 \\
\hline
\end{tabular}


Int.J.Curr.Res.Aca.Rev.2016; 4(3): 220-225

Table.2 Diastolic Blood pressure of patients between two groups

\begin{tabular}{lccc}
\hline & \multicolumn{2}{c}{ Group } & $\mathrm{P}$ \\
& Sevofloran & Remifantanil & \\
\hline Before induction & $56.77 \pm 12.08$ & $58.06 \pm 15.00$ & 0.632 \\
After Induction & $53.53 \pm 10.01$ & $50.59 \pm 8.71$ & 0.106 \\
15 min after Induction & $48.44 \pm 8.44$ & $45.67 \pm 11.15$ & 0.146 \\
30 min after Induction & $47.84 \pm 8.86$ & $44.35 \pm 9.09$ & 0.044 \\
45 min after Induction & $51.29 \pm 47.36$ & $42.84 \pm 9.06$ & 0.196 \\
60 min after Induction & $45.45 \pm 11.06$ & $44.02 \pm 9.56$ & 0.468 \\
75 min after Induction & $45.07 \pm 10.83$ & $47.02 \pm 11.11$ & 0.355 \\
90 min after Induction & $44.87 \pm 10.18$ & $46.85 \pm 8.80$ & 0.278 \\
105 min after Induction & $44.35 \pm 8.83$ & $46.47 \pm 9.34$ & 0.246 \\
120 min after Induction & $45.50 \pm 12.43$ & $48.28 \pm 11.74$ & 0.308 \\
135 min after Induction & $44.04 \pm 10.69$ & $47.93 \pm 10.18$ & 0.185 \\
150 min after Induction & $40.75 \pm 9.65$ & $47.28 \pm 9.06$ & 0.109 \\
165 min after Induction & $39.25 \pm 2.75$ & $47.08 \pm 9.66$ & 0.025 \\
180 min after Induction & $44.33 \pm 15.37$ & $56.00 \pm 21.83$ & 0.469 \\
\hline
\end{tabular}

Table.3 Mean Arterial Blood pressure of patients between two groups

\begin{tabular}{lccc}
\hline & \multicolumn{2}{c}{ Group } & P \\
& Sevofloran & Remifantanil & \\
\hline Before induction & $71.84 \pm 10.50$ & $71.88 \pm 16.40$ & 0.989 \\
After Induction & $68.28 \pm 10.77$ & $64.55 \pm 9.31$ & 0.061 \\
15 min after Induction & $63.93 \pm 9.86$ & $59.35 \pm 8.70$ & 0.012 \\
30 min after Induction & $63.73 \pm 9.79$ & $59.67 \pm 8.57$ & 0.025 \\
45 min after Induction & $61.36 \pm 9.54$ & $57.81 \pm 8.76$ & 0.048 \\
60 min after Induction & $62.16 \pm 11.69$ & $59.26 \pm 9.52$ & 0.161 \\
75 min after Induction & $61.64 \pm 11.69$ & $61.58 \pm 8.60$ & 0.979 \\
90 min after Induction & $61.17 \pm 11.22$ & $62.72 \pm 8.91$ & 0.431 \\
105 min after Induction & $61.51 \pm 10.63$ & $62.35 \pm 9.00$ & 0.675 \\
120 min after Induction & $62.56 \pm 12.35$ & $63.28 \pm 10.90$ & 0.786 \\
135 min after Induction & $60.38 \pm 11.34$ & $63.73 \pm 11.21$ & 0.298 \\
150 min after Induction & $60.63 \pm 9.71$ & $63.63 \pm 9.98$ & 0.491 \\
165 min after Induction & $58.50 \pm 2.08$ & $61.18 \pm 9.91$ & 0.608 \\
180 min after Induction & $57.33 \pm 12.34$ & $62.33 \pm 4.93$ & 0.550 \\
\hline
\end{tabular}


Int.J.Curr.Res.Aca.Rev.2016; 4(3): 220-225

Table.4 Heart Rate of patients between two groups

\begin{tabular}{lccc}
\hline & \multicolumn{2}{c}{ Group } & P \\
& Sevofloran & Remifantanil & \\
\hline Before induction & $109.09 \pm 12.95$ & $115.75 \pm 13.83$ & 0.012 \\
After Induction & $109.20 \pm 14.43$ & $113.98 \pm 16.38$ & 0.110 \\
15 min after Induction & $112.13 \pm 12.86$ & $107.81 \pm 15.23$ & 0.113 \\
30 min after Induction & $111.64 \pm 14.53$ & $101.94 \pm 15.25$ & 0.001 \\
45 min after Induction & $109.44 \pm 12.64$ & $100.46 \pm 14.87$ & 0.001 \\
60 min after Induction & $109.25 \pm 11.95$ & $100.78 \pm 14.65$ & 0.001 \\
75 min after Induction & $108.58 \pm 11.93$ & $102.19 \pm 15.35$ & 0.017 \\
90 min after Induction & $109.20 \pm 10.52$ & $104.43 \pm 16.04$ & 0.070 \\
105 min after Induction & $109.06 \pm 12.24$ & $106.94 \pm 16.30$ & 0.466 \\
120 min after Induction & $109.20 \pm 12.57$ & $105.79 \pm 16.59$ & 0.306 \\
135 min after Induction & $107.64 \pm 15.17$ & $104.38 \pm 14.02$ & 0.403 \\
150 min after Induction & $109.88 \pm 15.85$ & $104.82 \pm 15.32$ & 0.454 \\
165 min after Induction & $113.50 \pm 8.54$ & $105.18 \pm 14.53$ & 0.466 \\
180 min after Induction & $108.67 \pm 9.87$ & $97.00 \pm 4.76$ & 0.307 \\
\hline
\end{tabular}

Concerning the heartbeat of patients of the two groups (Tables 2-4), the heartbeat of group B before induction was significantly higher, and the heartbeats of group A 30, 45, and 60 minutes after induction were significantly higher. However, no significant difference was observed between the two groups at other times.

Cochlear implant (CI) is a device that relatively substitutes for cochlea and converts sound energy to electric signals. In this device, each electrode directly stimulates the hearing nerves, and the electrical stimulations required for evoking hearing varies by person. Hence, each patient's speech processor has to be adjusted specifically for that patient, and this process is called mapping or programming (1-5).

During the surgery, it is important to the surgeon that the patient's blood pressure remains low so that the surgery is improved. Hence, selection of the proper medicine for induction and hypotension control is important. Our results suggest that during the cochlear implant surgery, use of inhalation anesthetics should be avoided for achieving proper hypotension because those dosages of inhalation drugs, which lead to hypotension, can suppress or even fully eliminate stapedius reflex.

\section{Conclusion}

During the surgery, it is important to the surgeon that the patient's blood pressure remains low so that the surgery is improved. Hence, selection of the proper medicine for induction and hypotension control is important. Our results suggest that during the cochlear implant surgery, use of inhalation anesthetics should be avoided for achieving proper hypotension because those dosages of inhalation drugs, which lead to hypotension, can suppress or even fully eliminate stapedius reflex. To obtained acceptable cochlear implant outcomes, the dynamic range has to be determined properly during the surgery.

\section{References}

1.Karatas E, et al. (2011) Intraoperative electrically evoked stapedius reflex thresholds in children undergone 
cochlear implantation: Round window and cochleostomy approaches. International Journal of Pediatric Otorhinolaryngology, 75, 1123-1126.

2.Crawford M.W, et al. (2009) DoseDependent Suppression of the Electrically Elicited Stapedius Reflex by General Anesthetics in Children Undergoing Cochlear Implant Surgery. Anesth Analg , 108, 1480 -7.

3.Gordon KA, Papsin BC, Harrison RV. (2004) Toward a battery of behavioral and objective measures to achieve optimal cochlear implant stimulation levels in children. Ear Hear, 25,44763.

4.Schultz A, Berger FA, Weber BP, Groven U, Niclaus O, Lu“ llwitz E, Schultz B. (2003) Intraoperative electrically elicited stapedius reflex threshold is related to the dosage of hypnotic drugs in general anesthesia. Ann Otol Rhinol Laryngol, 112,1050-5.

5.Sukhminder Jit Singh Bajwa, Ashish Kulshrestha .(2013) The cochlear implantation surgery: A review of anesthetic considerations and implications. International Journal of Health and Allied Sciences, 2(4), 225229.

6.B. Schultz Et al. (2003)Influence of EEG monitoring on intraoperative stapedius reflex threshold values in cochlear implantation in children. Paediatric Anaesthesia, 13, 790-796.

7.Trends in cochlear implant 'Fan-Gang Zeng; Trends in Amplification ‘Vol. 8, 1-34, 2004.

\section{How to cite this article:}

Masoud Naderpour, Yalda Jabbari Moghaddam, Mehdi Banaei, Kasra Tavasoli and Mahnin Seyed Hejazi. 2016. Evaluation of volatile and intravenous anesthetics effects on the hemodynamic state in children undergoing cochlear implant surgery. Int.J.Curr.Res.Aca.Rev.4(3): 220-225. doi: http://dx.doi.org/10.20546/ijcrar.2016.403.024 